\title{
Feminist Implications of Model-Based Science
}

\author{
Angela Potochnik
}

\begin{abstract}
Recent philosophy of science has witnessed a shift in focus, in that significantly more consideration is given to how scientists employ models. Attending to the role of models in scientific practice leads to new questions about the representational roles of models, the purpose of idealizations, why multiple models are used for the same phenomenon, and many more besides. In this paper, I suggest that these themes resonate with central topics in feminist epistemology, in particular prominent versions of feminist empiricism, and that model-based science and feminist epistemology each has crucial resources to offer the other's project.
\end{abstract}

\section{Introduction}

This paper has two aims, for two audiences. For those who examine how social values find their way into the products of science, I aim to show that the features of what has been termed model-based science are central to that project. For those who attend to the role of models in scientific practice, I aim to show that themes of feminist epistemologyparticularly the views labeled feminist empiricism - provide necessary parts of a full picture of model-based science. Scientific models and the role of social values both are themes in recent philosophy of science, but these topics have largely been treated independently. Much stands to be gained from developing views on these topics in tandem. 
The potential for expansion can be illustrated by a current debate in evolutionary biology about sexual selection theory. At its most basic, sexual selection theory posits competition among members of the same sex (and the same species) for mating opportunities with members of the opposite sex, and it is associated with a variety of further hypotheses surrounding the evolution of sex and sex-linked traits. Roughgarden (2009) criticizes sexual selection theory on a variety of grounds, and she suggests what she terms "social selection theory" as an alternative. Roughgarden posits that the traits that sexual selection theory is supposed to explain are better understood as adaptations to a range of social interactions, including mating, but also including offspring-rearing, coalition-building, etc., and that these interactions often lead to cooperative outcomes. ${ }^{1}$

Elements of this debate suggest that what is at issue is the choice among competing modeling approaches. Sexual selection theorists advocate extending and revising the traditional sexual selection framework to accommodate scenarios that do not appear to conform to it (e.g. Clutton-Brock, 2009). Roughgarden instead proposes that a wholly different modeling approach better represents the evolution of sex and reproduction. At issue is a disagreement over whether sexual and reproductive traits generally conform to a pattern of cooperation or conflict. On this interpretation, sexual selection theory and Roughgarden's alternative social selection theory are proposed modeling approaches with similar ranges of target phenomena and different representations of the targets' key features. This is an ongoing episode of science, so the resolution is not yet known. Notice, though, that both sexual selection theory and social selection theory may be accurate to some degree, with each representing certain features of the evolution of sex and reproduction. Indeed, Roughgarden allows that some traits are best described in terms of competition, and sexual selection theorists grant that not all mating behavior matches the classic sexual selection scenario (Clutton-Brock, 2007).

\footnotetext{
${ }^{1}$ See (Milam et al., 2011) for an analysis of Roughgarden's project.
} 
Yet this construal omits an important element of the debate, which comes to light when one considers why Roughgarden places such emphasis on cooperation. Roughgarden is clear on this point: she values cooperation and regard for others, which inspires her to reexamine evolutionary phenomena presumed to be explained by sexual conflict (Roughgarden, 2009; Roughgarden, in conversation). Social values are thus explicitly invoked in this debate. Each side accuses the other of imposing a favored worldview by privileging cooperation or conflict (Coyne, 2004; Roughgarden, 2009). However, as I pointed out above, it may be that sexual selection theory and Roughgarden's social selection theory are both successful modeling strategies. There is a puzzle, then, in how to account for the role of social values in this episode of science, since they do not lead to directly opposed empirical claims.

Near the end of this paper, I suggest an interpretation of the sexual selection/social selection debate that integrates both of these elements. That interpretation serves to illustrate the implications of model-based science for feminist epistemology, and vice versa. To get there, I first develop parallels between philosophical treatments of model-based science and a prominent approach to feminist epistemology of science (Section 2). These parallels provide mutual support for some of the considerations of feminist epistemology and scientific modeling; they also offer promising interpretations of some projects of feminist epistemology, and valuable extensions of accounts of model-based science. Then, in Section 3, I use insights from model-based science to help motivate the expansion of feminism into non-epistemic elements of philosophy of science, including model-construction, idealization, the selection of causal variables, and scientific explanation. ${ }^{2}$ Indeed, the expansion is bidirectional, for feminist philosophy of science is well-situated to provide conceptual resources for modelbased science as well.

\footnotetext{
${ }^{2}$ The term "epistemic" has multiple meanings in philosophy of science. Throughout this paper I employ the term simply to refer to the aspects of science related to the search for truth, viz., related to scientific epistemology. Hence I label "non-epistemic" all other aspects of science. The term is alternatively used to distinguish among types of influences on science, i.e. the properly epistemic from the social/non-epistemic; I do not use that terminology nor that distinction here.
} 


\section{Approaches to Pluralism: Models and Feminism}

\subsection{Model-Based Science}

Over the past several decades, models have received increasing attention in philosophy of science. However, coverage is somewhat fractured among distinct literatures, and the term "model" has been used in different ways for different projects. Models initially rose in prominence with the emergence of the semantic theory of science (Suppe, 1977), and in van Fraassen's (1980) formulation of constructive empiricism. ${ }^{3}$ In both uses, models were taken to be mathematical structures that serve as interpretations of scientific theories - viz., models in the logicians' sense. Giere (1988) took a somewhat different view of models, starting from the overt idealizations prominent in science textbooks - frictionless pendulums, bodies subject to no external forces, etc. Giere too notes the overlap with the terminology of logicians, for whom a model is an object satisfying some set of axioms. Nonetheless he is critical of van Fraassen's idea that models should be isomorphic to real-world systems, suggesting instead that the important relationship between models and reality is one of similarity.

Giere's (1988) view of the role of models in science inspired another literature on scientific modeling, one that is prominent in current philosophy of science. ${ }^{4}$ This tradition emphasizes models' incorporation of abstractions and idealizations, and thus only partial representation of real-world systems. Early inspiration for this approach was also drawn from Levins (1966), who addresses population biology in particular, as well as Wimsatt (1987). Emphasis is placed on accounting for the role of models in actual scientific practice, including how models can be employed independently of theory or without the aim of immediately representing a real-world system. A focus on modeling brings to the fore non-epistemic questions about

\footnotetext{
${ }^{3}$ Though see also (Hesse, 1966) for an early account of models in science.

${ }^{4}$ Note, however, that models are also still discussed in connection with the semantic view (da Costa \& French, 2000) and undoubtedly in other literatures as well. Godfrey-Smith (2006) discusses the differences between these treatments.
} 
science (Giere, 1988), including the nature of representation, the purpose of idealization, the explanatory roles of models, and others.

In this paper, my focus is model-based science: a distinctive approach to doing science that is based on the construction and analysis of models (Godfrey-Smith, 2006; Weisberg, 2007b). Giere (1988) points out that observations of science as it is practiced shows that models occupy center stage. Indeed, most philosophical treatments of model-based science are committed to reflecting actual scientific practice. For example, both Levins (1993) and Odenbaugh (2003) appeal to the accurate representation of scientific practice as part of their defense of the existence of tradeoffs among modeling approaches (both in response to Orzack \& Sober (1993)). Additionally, though (Giere, 1988) addresses physics, the discussion of model-based science has largely focused on biology (e.g. Beatty, 1980a,b; Plutynski, 2000, in addition to Levins, 1966; Orzack \& Sober, 1993; Levins, 1993; Odenbaugh, 2003).

The prominent aspects of model-based science addressed by philosophers stem from a focus on representation-roughly, the similarity relation that Giere (1988) posits between a model and a real-world system. Godfrey-Smith (2006) and Weisberg (2007b) contrast direct and indirect representation. In what Weisberg terms abstract direct representation, the aim is simply to describe an actual system in order to investigate it directly. In contrast, the aim of modeling is to indirectly represent a real-world system by describing a simpler, hypothetical system and investigating that simpler system, in order to draw conclusions about the actual system of interest. Broadly, scientific models are treated as a kind of intermediary - between investigations and the world in their role as indirect representations, and between explanations and the world insofar as they are used to generate understanding (Cartwright, 1983; Woodward, 2003).

In virtue of the strategy of indirect representation, models often represent their target systems only partially. They bear some features in common, while others are neglected or falsified. This is accomplished via the use of abstractions - the neglect of some 
features - or idealizations - incorporating unrealistic features (Wimsatt, 1987; Weisberg, 2007a; Batterman, 2009). It is thus common to employ a variety of models, with different combinations of simplifying assumptions, and to use comparisons to help distinguish central features of the models from artifacts of the idealizations. This is called robustness analysis (Levins, 1966; Wimsatt, 1981; Weisberg, 2006b). There is also the question of whether different desiderata, such as generality and accuracy, call for the development of different types of models - i.e., whether there are tradeoffs among the aims of models (Orzack \& Sober, 1993; Levins, 1993; Odenbaugh, 2003; Matthewson \& Weisberg, 2009). In what follows, I explore how these and related features of model-based science resonate in valuable ways with feminist approaches to philosophy of science.

\subsection{Parallels with Feminist Empiricism}

The past several decades have witnessed a variety of feminist concerns about and approaches to epistemology and science. A range of very different views all go by the name of feminist epistemology or philosophy of science. ${ }^{5}$ Two types of views are particularly relevant to the current project: feminist empiricism and standpoint epistemology. Early versions of feminist empiricism offered the most conservative feminist approach to science. Their aim was to show how sexism and other social biases have permeated science and to appeal to traditional scientific norms of objectivity and empiricism to correct such biases. A stronger alternative is standpoint epistemology, according to which women and others traditionally occupying disadvantaged social roles may gain epistemic privilege by reflecting on their subjugation. This is a less conservative position, for it introduces considerations that warrant revisiting traditional scientific norms. Several more recent feminist epistemologies have moved toward

\footnotetext{
${ }^{5}$ The terms "feminist epistemology" and "feminist philosophy of science" are largely used interchangeably (e.g. Anderson, 2010). The question of how we know becomes, for science, the questions of what counts as evidence, and what the relationship is between theory and evidence. These are the primary concern of feminist theories of science.
} 
a middle ground between the classic versions of feminist empiricism and standpoint theory (Intemann, 2010), including the recent articulations of feminist empiricism on which I will focus in this paper.

Longino (1990, 2001) and Nelson (1990) have developed influential versions of feminist empiricism. Whereas it has often been assumed that social influences can only undermine scientific objectivity, thereby resulting in bad science, Longino and Nelson attempt to reconcile the ubiquity of social and cultural influences on science with the achievement of objectivity. Central both to Longino's and Nelson's accounts is the role played by communities in science. According to Nelson, communities are in fact the "knowers"the entities that acquire knowledge. Social values shape community practices, so values in turn find their way into scientific practice. This can occur as influence on what studies are undertaken, in judgments of theories' prima facie plausibility, in what standards of evidence are accepted, and in how underdetermination among competing theories is resolved. Longino (2001) investigates how social values influence the range of assumptions that mediate the relationship between hypotheses and data. In Longino's view, it is those assumptions, and the related research goals, that actually define a scientific community.

Yet there is a difference between how Longino and Nelson envision the role of community in science. Both stress that the influence of social values on science is subject to critical scrutiny, but they differ on how that critical scrutiny plays out. Longino's pluralism arises from her commitment to "local epistemologies." This is the idea that many distinct communities exist within science, each governed by their own epistemic commitments, arising from their own background assumptions and goals. Some epistemic standards, such as empirical adequacy, transcend individual subcommunities, enabling each subcommunity's theories and methods to be subject to external criticism. Yet, because subcommunities differ in other epistemic commitments, there persists a plurality of theories and methods. These epistemic subcommunities thus embody the limits of empirical determination. In contrast, 
Nelson emphasizes the contiguity of the scientific community with the broader community; for her, the community of science is in fact the solution to the limits of empiricism.

Other features of Longino's and Nelson's accounts will emerge later in this discussion. For both, their versions of feminist empiricism at once adhere to the norm of evidencedriven science and yet authorize a role for social values in science. The resulting view resonates in interesting ways with the account of model-based science surveyed in Section 2.1. Moreover, feminist empiricism and model-based science are well-positioned to offer support and theoretical advancement for each others' purposes, in virtue of their connections and parallels.

Like the literature on scientific modeling, feminist epistemology has focused largely on biology and the social sciences (e.g. Harding \& Hintikka, 1983, Fox Keller, 1983). Additionally, as both Longino and Nelson stress, the goal of feminist epistemology is to attend to science as it is actually practiced, instead of merely considering a disembodied set of theories. These two similarities with treatments of model-based science are superficial, but they are not insignificant. Focusing on actual scientific practice, as it plays out in a variety of fields of sciences, leads away from a monolithic, "rational reconstruction" view of science, and toward views that can accommodate a variety of scientific approaches and goals. This is consistent with the aims of feminist epistemology and the aims of the literature on model-based science.

Feminist epistemology and accounts of model-based science also employ somewhat parallel approaches to making sense of this variety of scientific approaches and goals. The recognition that model-based science requires simplifying idealizations is similar to feminist discussions of "framework assumptions," such as representing humans as self-interested rational agents (Longino, 1990; Anderson, 2010). Feminist epistemologists see this as one aspect of science that is influenced by social values. Another perceived role for social values is as an influence on the "epistemic virtues" of scientific theories, and how these virtues 
are weighted (Longino, 2001). Widely endorsed epistemic values such as the simplicity, generality, and even the empirical adequacy of theories are, according to Longino, actually special to particular scientific communities. A scientific community selects the epistemic virtues to which it subscribes, and this choice is influenced by the aims and values the group has inherited. Longino points out that even empirical adequacy is negotiable, for one may choose to sacrifice some precision or accuracy to satisfy an alternate epistemic virtue $(185,186)$. This last point is strongly reminiscent of the literature on tradeoffs in model-based science. The idea of tradeoffs is inspired by Levins' (1966) view that models in population biology cannot be at once maximally accurate, precise, and general. This point has been used to motivate the idea that some models should sacrifice a degree of precision to purchase greater realism and generality, which enables them to represent a broader range of similar systems (Weisberg, 2006a). Treatments of model-based science thus share with feminist philosophy of science the recognition that simplifying assumptions are rampant and ineliminable from science, and the related idea that some precision or realism may be sacrificed to further other scientific goals.

This parallel also provides an opportunity for feminist philosophy of science to motivate an extension of accounts of model-based science. Tradeoffs among modeling desiderata is a plausible framework for interpreting Longino's view that commitments to epistemic virtues differ among sub-communities of science, at least in part because of divergent social values. Weisberg (2006a) focuses on the choice to sacrifice some precision in order to increase the generality of a model, on the grounds that this results in models that are well-suited to serve as explanations. Yet this is but one possible type of tradeoff. Another is, for instance, the choice to sacrifice some generality in order to increase the realistic representation of complex, highly variable interactions. ${ }^{6}$ This can be seen as a preference for complexity over

\footnotetext{
${ }^{6}$ Generality is here understood as Weisberg's p-generality (2006a), viz., in terms of range of applicability to possible systems. I take this form of generality to be equivalent to the abstractness of a model; see (Potochnik, 2010b) for elaboration on this point.
} 
simplicity, one of the non-traditional epistemic virtues Longino discusses. Other things equal, a more abstract model will have fewer parameters: it will be simpler and, in virtue of lower expectations of fidelity, applicable to a broader range of systems. Additional parameters enable a more realistic, higher fidelity representation of a complex system, but this also will decrease the model's generality. Which approach should be pursued depends on the modeler's aims and can be influenced by weighing commitments to simplicity versus attending to complex interactions, i.e., two of the conflicting epistemic virtues Longino describes. This is an extension of the account of tradeoffs central to model-based science, but in my view, a highly plausible extension. ${ }^{7}$

Model-based science is also well-situated to provide a plausible interpretation of Longino's claim that adherence to different epistemic virtues provide "different knowledge" about a single phenomenon (Longino, 2001, p.189). ${ }^{8}$ Modeling, in contrast to abstract direct representation, leads to the deemphasis of complete accuracy, and accordingly, of truth. According to Giere (1988),

That theoretical hypotheses can be true or false turns out to be of little consequence. To claim a hypothesis is true is to claim no more or less than that an indicated type and degree of similarity exists between a model and a real system. We can therefore forget about truth and focus on the details of the similarity (81).

With this shift, it is easy to imagine how commitments to different epistemic virtues could lead to "different knowledge," as Longino phrases it. Different models will represent different features of a system, at different degrees of abstraction; they will employ different idealizations; and they will generalize to different ranges of other systems. On this

\footnotetext{
${ }^{7}$ Further support for this extension is provided by the discussion in Section 3 of social values' influence on explanatory practice. Insofar as tradeoffs are made to facilitate explanation, attending to different causal patterns in pursuit of explanation will lead to different types of tradeoffs.

${ }^{8}$ Indeed, Longino (2000) discusses how a focus on scientific modeling increases the plausibility of this idea.
} 
interpretation, a commitment to the idea that different values generate different scientific knowledge about a single phenomenon does not involve granting the truth of multiple claims that are mutually inconsistent. Instead, it amounts to the much less problematic idea that multiple models provide different representations of the target system.

This interpretation of Longino's view makes clear that both feminist science and modelbased science are committed to the persistence of multiple approaches. Longino (2001) says, "local epistemologies enable us to think of situations characterized by a plurality of theories and models in a pluralist framework, rather than as a sign of the immaturity of a given field of research" (188). On this view, Kuhn (1962) was wrong to see a plurality of approaches as a sign that a field has not yet reached normalcy; it is instead a permanent feature of science. Model-based science embodies this pluralism. Multiple modeling approaches persist because they satisfy different representational aims; accomplish different tradeoffs among opposed virtues like generality, accuracy, and precision; and allow for comparisons among models with different assumptions, such as occurs with robustness analysis. This echos feminist empiricists' analysis of how social values influence the production of science: in the choice of causal variables to focus upon (Longino, 1990), in what epistemic virtues are adopted, and in how they are weighted (Longino, 2001), all of which open to both internal and external critique. It also offers an interpretation of the epistemic interdependence that Nelson (1990) emphasizes. $^{9}$

With this pluralism also comes a shared emphasis on situated, or perspectival, knowers and knowledge (cf. van Fraassen, 2008). This helps to motivate feminist epistemologists' emphasis on first-person and embodied knowledge, and the importance of science performed by individuals with a range of cognitive styles (Anderson, 2010). Social epistemology is thus a natural bedfellow of model-based science. Wimsatt (1987) sums up why this would be;

\footnotetext{
${ }^{9} \mathrm{~A}$ case study of epistemic interdependence for models of evolution by natural selection is detailed in (Potochnik, 2010a).
} 
he says, "any model must make some assumptions and simplifications, many of which are problematic, so the best working hypothesis would be that there are no bias free models in science" (24). Feminist epistemology can provide the resources to manage this rampant bias accompanying model-based science. On the accounts of feminist empiricism considered here, problematic simplifications and assumptions are controlled for by the development of models with contrary simplifications and assumptions. The differently biased models developed by differently situated scientists maintain a pluralistic science, but they also provide a route to (community) knowledge and objectivity.

In turn, accounts of model-based science offer a way to conceptualize the mediation of disagreements among different local epistemologies. By deemphasizing truth in favor of similarity relations, models distance themselves from absolute epistemic commitments. If researchers are aware of the simplifying assumptions they make, this leads to an appreciation of the limited representational roles of their models, which facilitates openness to other modeling approaches. This enables a sort of detachment from absolute claims about realworld dynamics. Godfrey-Smith (2006) suggests that,

When much day-to-day discussion is about model systems, disagreement about the nature of a target system is less able to impede communication. The model acts as a buffer, enabling communication and cooperative work across scientists who have different commitments about the target system (739).

This is how, for example, biologists can usefully discuss the dynamics of a game theory model of animal behavior, though they disagree on the significance of the model for actual evolutionary history. Thus, model-based science can facilitate communication and mediate disagreements in a pluralistic scientific community by distancing modeling approaches from truth-claims. This allows alternate approaches to be acknowledged and models to be fruitfully discussed, even in the face of disagreements about their applications. 
I have suggested several parallels and mutual supports between feminist empiricism and model-based science; these are summarized in Table 1. The parallels begin with a shared focus on actual scientific practice as it plays out in a variety of fields. This leads to an appreciation for the variety of approaches employed, and how each offers, at best, partially successful representation instead of total accuracy. Simplifying idealizations, also termed framework assumptions, are inescapable. Multiple modeling approaches, with different representational aims, thus can simultaneously flourish, for each provides different perspectival knowledge. Here feminist empiricism has something to offer accounts of modelbased science. Feminist empiricism's conception of the commitments scientific communities have to different epistemic virtues provides a reason to expect divergences in modeling aims, what aspects of a target system are focused upon, and what similar systems inform the inquiry. All lead to different tradeoffs among modeling desiderata. Moreover, feminist epistemologists emphasize that these are all avenues for social values to exert influence on science. Yet pluralism in science simultaneously exerts a corrective influence on biases, and here accounts of model-based science supplement feminist analyses. A multiplicity of modeling approaches makes room for models with opposed assumptions and idealizations. These are helpful in demonstrating how conclusions depend upon specific, problematic assumptions, and which conclusions are robust across a range of assumptions. Finally, this

pluralism allows disagreements about ultimate truths of the world to persist, even as there is agreement on the partial success of a variety of models.

\section{Beyond Feminist Epistemology}

There is something of a mismatch that accompanies the parallels I outlined above between feminist empiricism and model-based science. Though each resonates with — and can offer conceptual resources to - the other, feminist empiricism is a view about the 


\begin{tabular}{|l|l|}
\hline model-based science & feminist empiricism \\
\hline simplifying idealizations & framework assumptions \\
\hline modeling tradeoffs & weighing of epistemic virtues \\
\hline different representational aims & different knowledge \\
\hline multiple modeling approaches & variety of local epistemologies \\
\hline $\begin{array}{l}\text { multiple models with competing } \\
\text { assumptions }\end{array}$ & $\begin{array}{l}\text { importance of a range of cognitive } \\
\text { styles }\end{array}$ \\
\hline $\begin{array}{l}\text { agreement about models; disagree- } \\
\text { ment about target systems }\end{array}$ & $\begin{array}{l}\text { communication among divergent } \\
\text { scientific communities }\end{array}$ \\
\hline
\end{tabular}

Table 1: Parallels between accounts of model-based science and feminist empiricism

epistemology of science, whereas model-based science draws attention toward a variety of non-epistemic features of scientific practice. This does not undermine the connection between feminist epistemology and the philosophical literature on modeling. Instead it provides an opportunity for the expansion of the role of feminism in philosophy of science.

The core idea of feminist empiricism is that social values play a proper role in the production of scientific knowledge. The natural first step of such a program is to demonstrate how social values influence not just what questions are investigated, but also what answers are found: hence a feminist epistemology (or epistemologies). But a similar question about the role of social values can be asked about other aspects of scientific practice. Attending to model-based science brings to light a range of non-epistemic aspects of science that are plausibly influenced by social values, in a manner consistent with but not exhausted by feminist epistemology.

The elements of model-based science discussed in Section 2.1 serve as an entry point into a range of possibilities. The indirect representation that models provide makes explicit that researchers choose which features of a real-world system to represent, and which to misrepresent with idealizations. This choice is plausibly guided by background concerns that include social values, whether consciously or not. This is akin to discussion in feminist philosophy of science of how social values can influence the choice of causal variables 
(Longino, 1990, 2001). Framing this as a choice about representation, a feature of models, makes clear that the issue is distinct from that of what causal factors are posited to exist. There is a corresponding choice to make regarding not only what features to idealize, but also the nature of simplifying assumptions to employ in their stead. This too is a place where social values can exert an influence distinct from their epistemic influence. A third, related opportunity for the influence of social values on model-based science arises with robustness analysis. Recall from above that robustness analysis is the comparison of models with different idealizations in order to distinguish important features of the models from artifacts. The choice of how to vary simplifying assumptions, and even what features to test for robustness, may bear the mark of social values.

Consider, for instance, the choice to represent human genes as comprising a single human genome, as was done in the Human Genome Project, or as distinct male and female genomes, as some advocated when the X chromosome was sequenced (Richardson, 2010). Richardson emphasizes that this is not an empirical question, but is instead a feature of model-choice. Both involve simplifying idealizations. Representing the human genome as unitary neglects a range of systematic differences among individuals, including between males and females, whereas the representation of distinct male and female genomes treats differences between sexes as analogous to differences between species. The different idealizations have non-trivial implications for genomic models. As Richardson demonstrates, this feature of modeling is plausibly influenced by social values, such as the desire to emphasize human diversity or human commonality, or to avert gender essentialism.

Scientific explanation is another non-epistemic aspect of science into which model-based science can offer inroads for feminist analysis. Explicit discussion of explanation is present in some feminist approaches to science, including in both Longino's and Nelson's accounts. Yet missing from those discussions is a treatment of explanation that is independent of scientific epistemology and theory confirmation. Different questions arise for scientific explanations 
than those surrounding the corroboration of hypotheses and theories, and the attributes of good explanations may differ from the attributes of well-corroborated theories. For instance, Sober (2003) argues that unification can be a valid criterion for judging the truth of a theory, but not for judging explanatory worth. More broadly, I argue elsewhere that formulating explanations and confirming theories play very different roles in science and, accordingly, motivate different, even opposed, practices (Potochnik, 2010a). Thus, I suggest that a full-fledged feminist approach to scientific explanation will be independent of feminist epistemology. Explaining via models enables a move in that direction.

Many have asserted a role for models in scientific explanations (e.g. Achinstein, 1965; Cartwright, 1983; Woodward, 2003; Batterman, 2009; Strevens, 2009; Bokulich, 2011). Here I will proceed under the assumption that this general view is right - that models at least sometimes serve as explanations. Because models only partially represent target systems, a model that explains does so in spite of lapses in the accuracy of its representation. This suggests that, as different models of a system vary in what they represent and what idealizations they employ, so too may explanations of the same event vary in what information they convey. Perhaps these varying explanations are appropriate for different aims, just as different models are appropriate for different aims. Granting models a role in explanation thus introduces the possibility of pluralism about explanation as well. ${ }^{10}$

By explanatory pluralism, I mean that, at least sometimes, the best explanation of a given event depends on additional factors, factors that vary. The possibility of explanatory pluralism ushered in by the view that models play a role in explanation creates another space for the influence of social values. Elsewhere I have argued that scientific explanations depend essentially on the context in which they are formulated (Potochnik, 2010a,b). The idea is that different causal patterns deserve explanatory focus, depending on the nature

\footnotetext{
${ }^{10}$ Here I have merely sketched one way in which model-based science may be used to (in part) motivate explanatory pluralism. This is not the only option; Strevens (2009), for instance, develops an account of explanation that assumes models explain, but is not pluralist in this way.
} 
of the research program for which the explanation is formulated. This does not mean that scientists make up whatever explanations they fancy, citing whatever causal factors interest them. Instead, explanations emerge from the interplay of corroborated causal claims and interest-driven choices about which of those causal claims are explanatory, and how they are to be represented in a model. It is this element of choice that enables social values to exert special influence on scientific explanations.

For an example, consider again the debate in evolutionary biology about sexual selection theory introduced at the beginning of this paper. Recall that sexual selection theory posits competition among members of the same sex for mating opportunities to account for a variety of sexual and reproductive traits, and Roughgarden (2009) criticizes these hypotheses and suggests what she calls "social selection theory" as an alternative. Roughgarden argues that the traits that sexual selection theory is supposed to explain are better explained as adaptations to a much broader range of social interactions, interactions that often lead to cooperative outcomes. As different accounts of the evolution of sex and reproduction, sexual selection theory and social selection theory may seem to offer contradictory explanations of animal behavior, but that is not quite right. As I pointed out above, each theory may apply to some evolutionary phenomena, as both sides acknowledge (Roughgarden, 2009; CluttonBrock, 2007). Sexual selection models and social selection models may even predict some of the same behavioral outcomes. Thus sexual selection explanations and social selection explanations need not be incompatible. Nonetheless, they differ in the role ascribed to sexual conflict or to mutual gain through cooperation, and this difference shows itself in the types of causal patterns the two emphasize. If patterns of sexual conflict and cooperation are both embodied in some range of behaviors, then both the sexual selection explanation and the social selection explanation may be successful. These two contextual explanations simply latch onto different causal patterns to which the scenario conforms. Contextual explanation makes possible the success of both explanations, but that success is relative to a background 
research agenda.

This version of explanatory pluralism provides a framework for understanding how social values influence scientific explanations: different social values can result in a focus on different causal patterns. Consequently, different systems of values can yield different proposed explanations - explanations that latch onto different causal patterns and that are formulated in the context of different research programs. This is one element of the debate over sexual selection theory versus social selection theory. Roughgarden and some sexual selection theorists accuse each other of imposing a favored worldview by privileging cooperation or sexual conflict, respectively (Coyne, 2004; Roughgarden, 2009). Part of their disagreement is over whether sexual and reproductive traits generally embody a pattern of cooperation or conflict. It may be that one of these patterns is entirely absent. On the other hand, both may be accurate to some degree, and hence explain some traits (in some contexts).

Thus, in my view, a feminist approach to explanation should acknowledge the contextdependence of explanations and investigate how social values shape the contexts. For reasons mentioned above, this role of social values should be distinguished from their epistemic role. Existing feminist analyses are evocative of the directions in which such an analysis would proceed, but there is room for expansion. To begin with, one may investigate the ways in which social values contribute to the production of multiple distinct explanations of a single phenomenon, how those are related to their respective contexts, and how this curtails comparisons of the worth of different explanations.

In this section, I have focused on how model-based science can be used to motivate the expansion of feminism into non-epistemic elements of scientific practice. Recall, though, that I intend a two-way expansion, for as shown in Section 2.2, feminist philosophy of science is also well-situated to provide conceptual resources for accounts of model-based science. Feminist empiricism attends to the influence of scientific communities, alternative epistemic virtues like the realistic representation of complex processes, the perspectival nature of 
knowledge, and how social values can play a legitimate role in science. These aspects of science all shape how model-building actually proceeds, so accounts of these features supplement accounts of model-based science. We have seen, for instance, how disagreements over sexual selection models and social selection models are influenced by different views about, as Roughgarden puts it, what is "basic to biological nature" (2009, 3), prime territory for the influence of social values. And in Section 2.2, it was shown how commitments to divergent epistemic virtues, also influenced by social values, can motivate different modeling strategies, with different tradeoffs. The insights of feminist empiricism thus help motivate the sort of pluralism that results from model-based science. Finally, feminist critiques of science help motivate the explicit use of models - and thus explicit acknowledgement of limitations and falsifications - over attempted or presumed direct representation of the world. Modelbased science and socially engaged science go hand in hand nicely.

\section{Acknowledgments}

Thanks to James Griesemer's and Roberta Millstein's philosophy of biology lab at UC Davis and to Michael Weisberg for helpful feedback on earlier drafts. I also appreciate the incredibly helpful comments of two anonymous referees for this journal. Research for this article was completed during a fellowship at the Michelle R. Clayman Institute for Gender Research.

\section{References}

Achinstein, P. (1965). Theoretical models. British Journal for the Philosophy of Science, $16(62), 102-120$.

Anderson, E. (2010). Feminist epistemology and philosophy of science. In E. N. Zalta (Ed.) The Stanford Encyclopedia of Philosophy. 
http://plato.stanford.edu/archives/fall2010/entries/feminism-epistemology, Fall 2010 ed.

Batterman, R. W. (2009). Idealization and modeling. Synthese, 169(3), 427-446.

Beatty, J. (1980a). Optimal-design models and the strategy of model building in evolutionary biology. Philosophy of Science, 47(4), 532-561.

Beatty, J. (1980b). What's wrong with the received view of evolutionary theory? PSA: Proceedings of the Biennial Meeting of the Philosophy of Science Association, Two: Symposia and Invited Papers, 397-426.

Bokulich, A. (2011). How scientific models can explain. Synthese, 180(1), 33-45.

Cartwright, N. (1983). How the Laws of Physics Lie. Oxford: Oxford University Press.

Clutton-Brock, T. (2007). Sexual selection in males and females. Science, 318, 1882-1885.

Clutton-Brock, T. (2009). Sexual selection in females. Animal Behaviour, 77, 3-11.

Coyne, J. (2004). Charm schools, review of Evolution's Rainbow, by J. Roughgarden. Times Literary Supplement.

da Costa, N., \& French, S. (2000). Models, theories, and structures: Thirty years on. Philosophy of Science, 6r(3), 127.

Fox Keller, E. (1983). A feeling for the organism: The life and work of Barbara McClintock. W.H. Freeman and Company.

Giere, R. N. (1988). Explaining Science; A Cognitive Approach. Chicago: University of Chicago Press.

Godfrey-Smith, P. (2006). The strategy of model-based science. Biology and Philosophy, $21,725-740$. 
Harding, S., \& Hintikka, M. (Eds.) (1983). Discovering Reality: Feminist Perspectives on Epistemology, Metaphysics, Methodology, and the Philosophy of Science. Dordrecht: D. Reidel Publishing Company.

Hesse, M. (1966). Models and Analogies in Science. Notre Dame: University of Notre Dame Press.

Intemann, K. (2010). Years of feminist empiricism and standpoint theory: Where are we now? Hypatia, 25(4), 778-796.

Kuhn, T. (1962). The Structure of Scientific Revolutions. Chicago: University of Chicago Press, 1 ed.

Levins, R. (1966). The strategy of model building in population biology. In E. Sober (Ed.) Conceptual Issues in Evolutionary Biology, (pp. 18-27). Cambridge: MIT Press, first ed.

Levins, R. (1993). A reply to Orzack and Sober: Formal analysis and the fluidity of science. The Quarterly Review of Biology, 68(4), 547-555.

Longino, H. E. (1990). Science as Social Knowledge: Values and Objectivity in Scientific Inquiry. Princeton: Princeton University Press.

Longino, H. E. (2000). Subjects, power, and knowledge: Description and prescription in feminist philosophies of science. In I. Bartsch, \& M. Lederman (Eds.) The Gender and Science Reader, chap. 17, (pp. 213-224). London: Routledge, 1st ed.

Longino, H. E. (2001). The Fate of Knowledge. Princeton: Princeton University Press.

Matthewson, J., \& Weisberg, M. (2009). The structure of tradeoffs in model building. Synthese, 170(1). 
Milam, E., Millstein, R., Potochnik, A., \& Roughgarden, J. (2011). Sex and sensibility: The role of social selection, a review symposium of roughgarden's The Genial Gene. Metascience, 20(2), 253-277.

Nelson, L. H. (1990). Who Knows: From Quine to a Feminist Empiricism. Philadelphia: Temple University Press.

Odenbaugh, J. (2003). Complex systems, trade-offs, and theoretical population biology: Richard Levins' 'the strategy of model building in population biology' revisited. Philosophy of Science, 70, 1496-1507.

Orzack, S. H., \& Sober, E. (1993). A critical assessment of Levins's 'The strategy of model building in population biology' (1966). Quarterly Review of Biology, 68(4), 533-546.

Plutynski, A. (2000). Modeling evolution in theory and practice. PSA: Proceedings of the Biennial Meeting of the Philosophy of Science Association, One: Contributed Papers, $225-236$.

Potochnik, A. (2010a). Explanatory independence and epistemic interdependence: A case study of the optimality approach. The British Journal for the Philosophy of Science, $61(1), 213-233$.

Potochnik, A. (2010b). Levels of explanation reconceived. Philosophy of Science, 777(1), $59-72$.

Richardson, S. S. (2010). Sexes, species, and genomes: Why males and females are not like humans and chimpanzees. Biology and Philosophy, 25(5), 823-841.

Roughgarden, J. (2009). The Genial Gene: Deconstructing Darwinian Selfishness. Berkeley: University of California Press. 
Sober, E. (2003). Two uses of unification. In F. Stadler (Ed.) The Vienna Circle and Logical Empiricism: Re-evaluation and Future Perspectives, (pp. 205-216). Kluwer.

Strevens, M. (2009). Depth: An Account of Scientific Explanation. Cambridge: Harvard University Press.

Suppe, F. (1977). The Structure of Scientific Theories. Urbana: University of Illinois Press, 2nd ed.

van Fraassen, B. C. (1980). The Scientific Image. Oxford: Clarendon Press.

van Fraassen, B. C. (2008). Scientific Representation: Paradoxes of Perspective. Oxford: Oxford University Press.

Weisberg, M. (2006a). Forty years of 'The Strategy': Levins on model building and idealization. Biology and Philosophy, 21, 623-645.

Weisberg, M. (2006b). Robustness analysis. Philosophy of Science, 73(5), 730-742.

Weisberg, M. (2007a). Three kinds of idealization. The Journal of Philosophy, 104(12), 639-659.

Weisberg, M. (2007b). Who is a modeler? The British Journal for the Philosophy of Science, $58,207-233$.

Wimsatt, W. C. (1981). Robustness, reliability, and overdetermination. In M. Brewer, \& B. Collins (Eds.) Scientific Inquiry and the Social Sciences, (pp. 124-163). San Francisco: Jossey-Bass.

Wimsatt, W. C. (1987). False models as means to truer theories. In N. Nitecki, \& A. Hoffman (Eds.) Neutral Models in Biology, (pp. 23-55). Oxford: Oxford University Press. 
Woodward, J. (2003). Making Things Happen: A Theory of Causal Explanation. Oxford: Oxford University Press. 